\title{
DYNAMIC MEASUREMENTS ON STAY CABLES OF CABLE-STAYED BRIDGES USING AN INTERFEROMETRY LASER SYSTEM
}

\author{
by Alvaro Cunha and Elsa Caetano \\ Department of Civil Engineering of the University of Porto \\ R. Bragas, 4099 Porto Codex, Portugal \\ E-mail: acunha@fe.up.pt
}

\section{INTRODUCTION}

Dynamic measurements on stay cables are often required to assess different problems of great interest in the context of the design, construction and maintenance of cable-stayed bridges, such as: (i) The evaluation of cable tensions, whose knowledge is critical to the correct alignment and distribution of internal forces in the finished bridge, and whose change in time can provide interesting indications concerning the structural health; (ii) The assessment of fatigue problems in stay cables caused by long-term traffic loads; (iii) The evaluation of the level of importance of cable vibrations, that can occur due to vortex-shedding phenomena, parametric or rain-wind excitation, and that have affected the behaviour of several important cable-stayed bridges, like Faroe, Helgeland, Ben-Ahin, Wandre ${ }^{1}$, Second Severn Crossing or Erasmus ${ }^{2}$ bridges; (iv) The experimental identification of local and global natural frequencies, which may contribute to validate and update finite element numerical models used to simulate the dynamic behaviour of the bridge under wind or seismic loads.

The most common way of making such dynamic measurements is based on the use of accelerometers conveniently attached to the external cable surface, which involves a rather hard and tedious set-up when dealing with the large number of stay cables, common in modern cable-stayed bridges. Therefore, in terms of practical applications, it is of utmost importance to develop and apply new measurement systems that enable systematic and accurate dynamic measurements on stay cables in a simple and comfortable way.

This paper stresses the interesting role that an interferometry laser system can play in this context, avoiding the direct contact with the structure, and shows a real application performed during the dynamic tests of the Vasco da Gama cable-stayed bridge, in Portugal, which clearly reveals the excellent accuracy and simplicity provided by this optical technique, when compared with a more conventional approach. 
The laser sensor used in this work (OMETRON, VPI system A) is an industrially engineered Doppler-based interferometer, which functions as a non-contacting velocity transducer capable of remote measurement of the velocity of a solid surface. The basic principle behind the laser Doppler technique used is that when a beam of coherent light is reflected from a moving surface, its frequency changes according to the wellknown Doppler effect. Although the fractional change of the frequency of the light wave is very small, it can be measured very accurately using optical interferometry in conjunction with electronic frequency measurement equipments, the velocity of the moving surface being directly derived from the frequency changes.

The VPI sensor is based on a Michelson interferometer, in which a laser beam is divided into reference and signal beams (Figure 1). The signal beam is directed onto the moving test surface and the back-reflected light is combined with the internal reference beam. The frequency of the reflected beam is shifted by an amount $F_{d}=2 v / \lambda$ in accordance with the Doppler effect, where $v$ is the velocity of the moving surface and $\lambda$ is the wavelength of the laser radiation. The intensity of the interference between the reference and signal beams is a signal with a frequency $F_{d}$ proportional to the velocity absolute value $|v|$. To also assess the sense of the surface motion, two independent detection channels of the interference intensity are used. The two channels are configured so that the output signals obtained are phase shifted by $\pm 90^{\circ}$, depending on the sense of the movement of the test surface. In practice, this is accomplished imposing an interferometer path difference presented to one channel one quarter of a wavelength longer than the presented to the other. These signals are electronically mixed with a frequency carrier and the resulting frequency shifted Doppler signal is converted to an analog voltage directly proportional to the instantaneous value of the surface velocity.

\section{THE VASCO DA GAMA CABLE-STAYED BRIDGE}

\section{Overall characteristics of the bridge}

The Vasco da Gama Bridge is the new Tagus River crossing in Portugal, 17300m long, including three interchanges, a $5 \mathrm{~km}$ long section on land and a continuous $12300 \mathrm{~m}$ long bridge. The Bridge was recently constructed close to the area of EXPO-98 international exhibition, in Lisbon, and includes a cable-stayed component (Figure 2) over the main navigation channel with $420 \mathrm{~m}$ central span and three lateral spans $(62+70.6+72 \mathrm{~m})$ on each side, corresponding to a total length of $829.2 \mathrm{~m}$ between transition piers. The deck is $31 \mathrm{~m}$ wide and is formed by two lateral prestressed girders, $2.6 \mathrm{~m} \mathrm{high,} \mathrm{connected} \mathrm{by} \mathrm{a} \mathrm{slab} \mathrm{and} \mathrm{by} \mathrm{transverse}$ steel I girders. It is continuous along its total length and it is suspended at level $52.5 \mathrm{~m}$ by two plans of 48 stays connected to each tower. The two $\mathrm{H}$ shaped towers are $147 \mathrm{~m}$ high above a massive zone at their base designed for protection against ship collision.

\section{Identification of main dynamic properties}

Due to the high proneness of long span bridges to aerodynamic instability problems, as well as to the high seismic risk of the Southern part of Portugal, the dynamic behaviour of Vasco da Gama cable-stayed bridge 
has been extensively studied using both experimental and numerical approaches ${ }^{3,4}$. In particular, dynamic tests have been performed by the University of Porto ${ }^{5}$ in order to experimentally identify the most relevant modal parameters of the cable-stayed bridge from the aerodynamic and seismic behaviour point of view, and correlate them with the corresponding parameters provided by the 3-D numerical model developed by EEG (Europe Études Gecti, Villeurbanne, France), using the finite element program Hercules.

The dynamic tests involved: (i) an ambient vibration test to identify global natural frequencies and mode shapes of the bridge, measuring the structural response at 29 different sections (upstream and downstream) along the deck and towers, using section 10 (Figure 3) as reference section; (ii) a free vibration test, based on the sudden release of a $60 \mathrm{t}$ mass excentrically suspended from the deck (Figure 4) at 1/3 of the main span (upstream), in order to accurately identify structural modal damping factors; (iii) dynamic measurements on stay cables, both under ambient excitation or during the free vibration test, in order to identify either global natural frequencies of the whole structure or local frequencies of the stay cables, and to indirectly measure the corresponding cables tensions; (iv) experimental evaluation of dynamic amplification factors (DAFs) associated to the passage of heavy traffic loads at different speeds, along several lanes.

The instrumentation used in the ambient and free vibration tests, as well as in the evaluation of DAFs, consisted of 6 independent triaxial accelerographs, which were appropriately programmed before each sequence of measurements, in order to begin the acquisition simultaneously every twenty minutes, in principle. Due to the very low frequency range of interest $(0-1 \mathrm{~Hz})$, the time of acquisition for each set up was always 16 minutes, so as to obtain average spectral estimates with a frequency resolution inferior to $0.01 \mathrm{~Hz}$ in the ambient vibration test and to record all the free vibration response of the bridge during the mass release test. The time left to change the position of the accelerographs between successive set ups, in the ambient vibration test, was of 4 minutes, except in the case of measurements along the towers, due to the necessity of climbing the stairs till the top, transporting the accelerographs in rock-bags. The use of this system, which provided a precision superior to $0.015 \mathrm{mg}\left(1 \mathrm{~g} / 2^{16}\right)$, due to the use of $16 \mathrm{bit} A / \mathrm{D}$ convertors, revealed to be quite practical and efficient, permitting the performance of the whole ambient vibration test in 2.5 days, avoiding completely the necessity of using long electric cables connecting the 18 force balance accelerometers to a conventional central data acquisition and processing system. The experimental data obtained was periodically downloaded to the hard disk of a portable PC and subsequently analysed and processed in order to extract global modal parameters of the bridge.

Table I summarises the values of natural frequencies of the bridge identified in the range $0-1.15 \mathrm{~Hz}$, in correspondance with natural frequencies provided by the numerical model. Figure 5 shows some of the identified modes of vibration, also presenting the corresponding numerical modes, as well as some modal components identified using the free vibration test. It's worth mentioning that, despite the relatively low level of signal captured during the ambient vibration test (between 0.36 and $12.5 \mathrm{mg}$ of maximum vertical acceleration at the reference section in the several records) and the high number of closely spaced natural frequencies in the range $0-1.15 \mathrm{~Hz}$, the evaluation of average normalised cross and auto power spectral 
density functions, with a frequency resolution of $0.006 \mathrm{~Hz}$, permitted the accurate identification of modal parameters using a conventional frequency domain approach. In some cases of higher modal interference, the free vibration test was specially useful, particularly in terms of the identification of modal damping factors, due to the much higher level of signal captured. Further details of this work are referred by Cunha et al in reference ${ }^{6}$.

Table I. Identified and calculated natural frequencies of the bridge

\begin{tabular}{ccc}
\hline $\begin{array}{c}\text { Calculated } \\
\text { frequencies }(\mathrm{Hz})\end{array}$ & $\begin{array}{c}\text { Identified natural } \\
\text { frequencies }(\mathrm{Hz})\end{array}$ & $\begin{array}{c}\text { Type of mode } \\
\text { of vibration }\end{array}$ \\
\hline 0.2624 & 0.298 & $1^{\text {st }}$ transversal bending \\
0.3185 & 0.341 & $1^{\text {st }}$ vertical bending \\
0.4287 & 0.437 & $2^{\text {nd }}$ vertical bending \\
0.4386 & 0.471 & $1^{\text {st }}$ torsion + transversal bending \\
0.6268 & $0.572 * / 0.590 * / 0.599 * / 0.619 * / 0.624^{*}$ & $2^{\text {nd }}$ torsion + transversal bending \\
0.6077 & 0.651 & $3^{\text {rd }}$ vertical bending \\
0.6268 & $0.693 * / 0.707 * / 0.718^{*} / 0.755^{*}$ & $2^{\text {nd }}$ torsion + transversal bending \\
0.7600 & $0.817 *$ & $4^{\text {th }}$ vertical bending \\
& $0.895 * / 0.917 *$ & $3^{\text {rd }}$ torsion \\
& 0.985 & $5^{\text {th }}$ vertical bending \\
& $1.129 *$ & $4^{\text {th }}$ vertical bending \\
\hline
\end{tabular}

(*) - multiple modes, low level of signal

\section{DYNAMIC MEASUREMENTS ON STAY CABLES}

\section{Identification of natural frequencies}

The measurement of vibrations in some of the longest stay cables of Vasco da Gama cable-stayed bridge was performed using both conventional piezoelectric accelerometers and the laser sensor previously described, in order to check the high interest of this optical transducer in terms of the experimental analysis and identification of the dynamic behaviour of stay cables and of the accurate evaluation of the corresponding cable tensions.

For that purpose, the accelerometers were screwed on small metallic cubes, conveniently attached to the external surface of the stay cables with the help of metallic belts strongly tightened. This relatively boring preparatory operation, only possible as the bridge was not open to the normal road traffic yet, was systematically repeated in all the stay cables observed, placing the accelerometers $5 \mathrm{~m}$ above the deck by means of a crane, and measuring vibrations in the vertical plane (Figures 6,7(a)). The use of the laser transducer became however incomparably easier, the only operation needed being the control of the position of the laser head, simply placed on the deck under each cable, in order to produce a laser beam hitting the cable surface at the section of application of the corresponding accelerometer (Figure 7(b)). Due to the significant inclination of the cables observed, the laser beam was positioned vertically, and the output signal of the laser sensor was directly connected with a spectral analyzer. No special targets were used for the laser beam, in order to improve the signal to noise ratio. It's still worth noting that, although a distance of observation of $5 \mathrm{~m}$ has been used to permit a correct comparison of results with the accelerometer, larger 
distances of observation of the laser sensor, of the order of several tenths of meters, can be used without considerable loss of accuracy, as previously shown by Cunha et al in reference ${ }^{7}$.

Figure 8 shows average power spectra associated to the ambient response of one of the longest stay cables of the bridge, obtained with simultaneous measurements at the same point on the basis of the two types of sensors mentioned, using 16 averages and a frequency resolution of $0.0078 \mathrm{~Hz}$. Although those spectra are associated to different mechanical quantities measured (acceleration and velocity), they clearly evidence an excellent agreement in terms of identification of local natural frequencies of the cable, characterised by equally spaced well pronounced peaks. Moreover, some global natural frequencies of the bridge, corresponding to main peaks of the spectra in the range $0-1 \mathrm{~Hz}$, are also apparent, though not so clearly in the case of the laser sensor, as this transducer measures the relative velocity between the deck and the stay cable. The same conclusion can also be drawn when comparing the natural frequencies identified using the laser sensor with those obtained with conventional equipment in the free vibration test (Figure 10). In this last case, the peaks related to global natural frequencies are still more evident, due to the much higher level of global vibrations recorded during the free vibration test. Figure 9 also presents a direct comparison between the acceleration average power spectra corresponding to both transducers, obtained performing a digital differentiation of the laser velocity signal, using a FFT algorithm, showing the excellent agreement achieved in the resonance zones and the lower noise level of the laser system.

The values of the first 5 natural frequencies of the stay cable observed, identified on the basis of these spectra using the two measurement systems referred, are virtually coincident $(0.594,1.180,1.766,2.367$, $2.953 \mathrm{~Hz}$ ), the only difference noted in one of the natural frequencies being equal to the frequency resolution $(0.0078 \mathrm{~Hz})$.

\section{Evaluation of cable tensions}

Several techniques can be employed to evaluate cable forces, namely measurement of the force in a tensioning jack, application of a ring load-cell, topographic measurements, elongation of the cables during tension and installation of strain gauges in the strands. As referred by $\mathrm{Casas}^{8}$, in spite of their simple theoretical bases, each of these methods is complex in its practical application and, in some cases, the level of accuracy is insufficient.

A relatively simpler and less expensive method to estimate cable tensions in cable-stayed bridges is based on the vibrating chord theory, taking into consideration the identified values of natural frequencies of the stay cables, which leads to the following relation:

$$
T=\frac{4 m f_{n}^{2} L^{2}}{n^{2}}
$$

where $T$ is the cable tension, $f_{n}$ is the n-th natural frequency, $L$ is the cable length and $m$ represents the mass of the cable per unit length. Application of this approach, taking $L=214.97 \mathrm{~m}$ and $\mathrm{m}=96.9 \mathrm{~kg} / \mathrm{m}$, leads to the values of cable tensions shown in Table II, considering the use of both measurement systems previously referred. 
Table II. Cable tensions $(\mathrm{kN})$ evaluated on the basis of the vibrating chord theory

\begin{tabular}{ccccccc}
\hline & $1^{\text {st }}$ freq. & $2^{\text {nd }}$ freq. & $3^{\text {rd }}$ freq. & $4^{\text {th }}$ freq. & $5^{\text {th }}$ freq. & Average \\
\hline Accelerometer & 6320 & 6235 & 6207 & 6272 & 6248 & 6256 \\
Laser sensor & 6320 & 6235 & 6256 & 6272 & 6248 & 6266 \\
\hline
\end{tabular}

\section{CONCLUSIONS}

Dynamic measurements on stay cables of cable-stayed bridges are currently performed both at construction and exploitation stages, using conventional accelerometers, which oblige to a rather hard and tedious set-up preparation when dealing with a large number of stay cables. The results presented herein clearly evidence the useful role that an interferometry laser sensor can play in this context, working as an alternative measurement system enabling the performance of extensive measurements without direct contact with the vibrating surface of the cables and providing a high level of accuracy, particularly in terms of identification of natural frequencies and cable tensions.

\section{References}

1. Cremer J-M, Cournasse C., Goyet V.V., Lothaire A. and Dumortier A., "The stays, their dynamic behaviour, their equipments - Bridges at Ben-Ahin, Wandre and upon Alzette", Proc. of the Int. Symposium on Cable Dynamics, Liège, Belgium, pp.473-480, 1995.

2. Geurts C., Vrouwenvelder P., Staalduinen P. and Reusink J., "Numerical Modelling of Rain-WindInduced Vibration: Erasmus Bridge, Rotterdam", Structural Engineering International, IABSE, Vol.8, No.2, pp.129-135, 1998.

3. Grillaud G., Bourcier P., Barré C. and Flamand O., "Wind action on the Vasco da Gama cable stayed bridge", Proc. of the $2^{\text {nd }}$ European and African Conference on Wind Engineering, Genova, Italy, pp.1449-1456, 1997.

4. Branco F., Mendes P. and Guerreiro L., "Research studies for the Vasco da Gama Project", IST Science \& Technology, No.2, pp.3-7, April 1998.

5. Delgado R., Cunha A., Caetano E. and Calçada R., "Dynamic Tests of Vasco da Gama Bridge" (in Portuguese), Report under contract with NOVAPONTE, Faculty of Engineering of the University of Porto, 1998.

6. Cunha A., Caetano E., Calçada R. and Delgado R., "Dynamic Tests on Vasco da Gama Cable-Stayed Bridge", Proc. of IABSE Conference on Cable-Stayed Bridges, Past, Present and Future, Malmö, Sweden, 1999.

7. Cunha A., Laje A., Gomes A. and Caetano E., "Accuracy evaluation of a laser interferometry measurement system in long distance dynamic measurements", Proc. of $7^{\text {th }}$ Int. Conf. on Computational Methods and Experimental Measurements, CMEM95, Capri, Italy, 1995.

8. Casas J.R., "A combined method for measuring cable forces: the cable-stayed Alamillo Bridge, Spain, Structural Engineering International, Journal of the IABSE, Vol.4, No.4, pp.235-240, November 1994. 


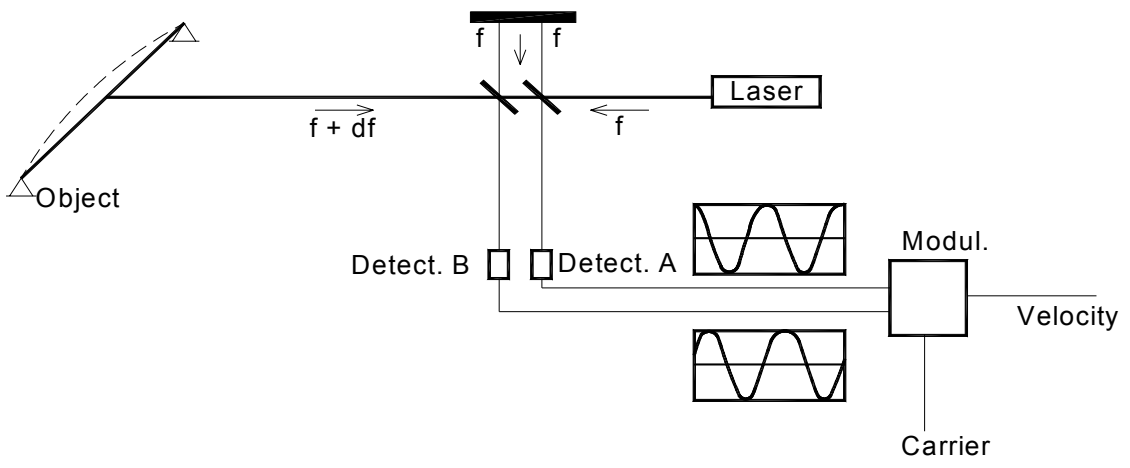

Fig. 1: Scheme of the interferometry laser technique used

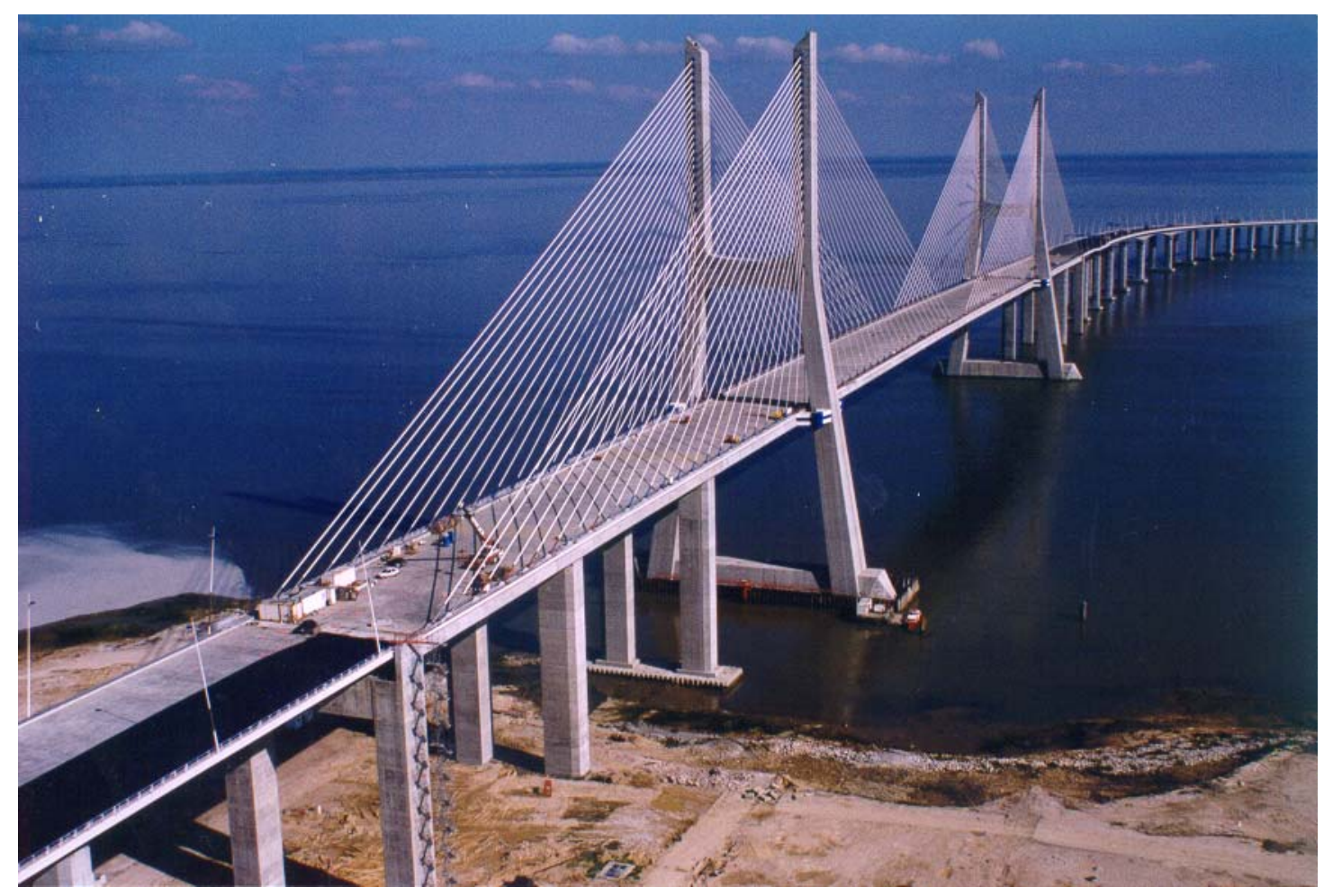

Fig. 2: Vasco da Gama cable-stayed bridge

$$
\text { (S) }
$$

Fig. 3: Schematic representation of the bridge with indication of the measurement sections used in the ambient vibration test 


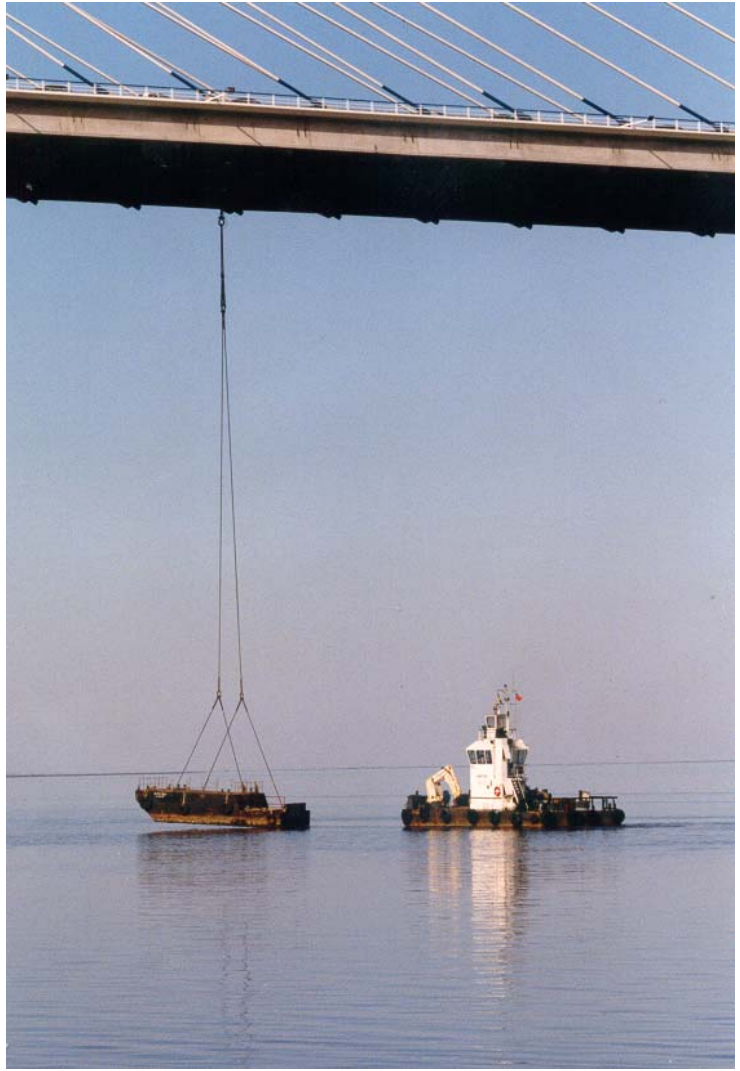

(a)

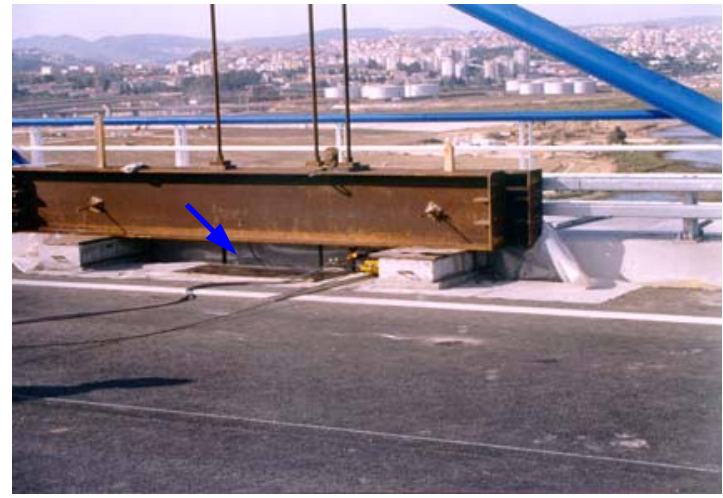

(b)

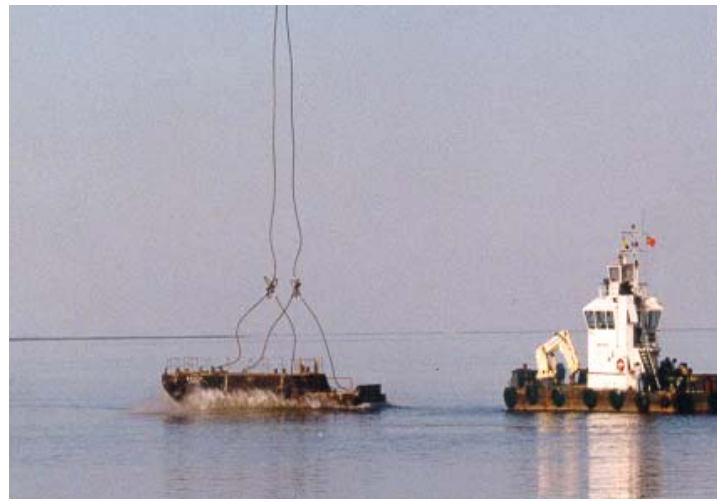

(c)

Fig. 4: Free vibration test: (a) Excentrically suspended 60t barge;

(b) Starting cut of hanging Dywidag bar; (c) Release of barge

Freq $=0.298 \mathrm{~Hz}-1 \mathrm{st}$ transversal bending mode

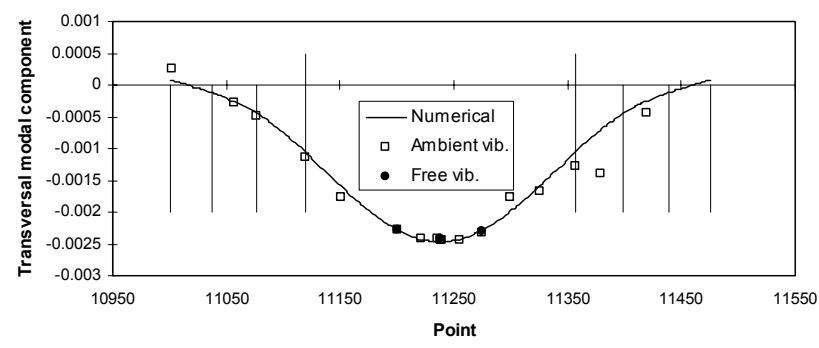

Freq. $=0.437 \mathrm{~Hz}-2 \mathrm{nd}$ vertical bending moment

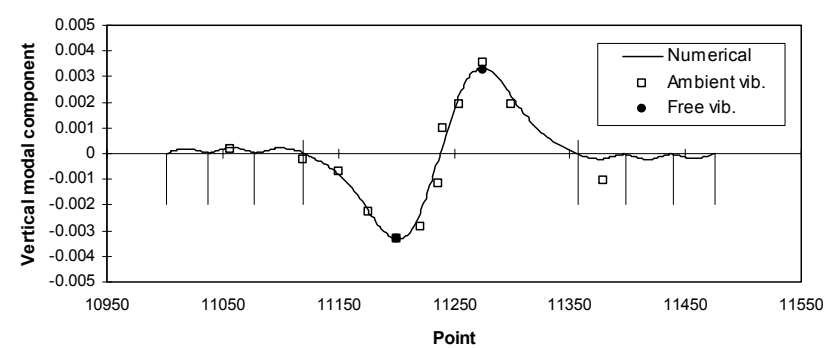

Freq. $=0.341 \mathrm{~Hz}-1 \mathrm{st}$ vertical bending mode

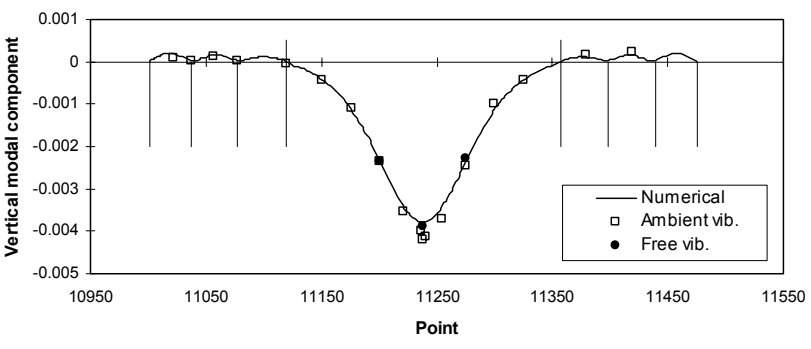

Freq. $=0.471 \mathrm{~Hz}-1 \mathrm{st}$ torsion + transversal bending mode

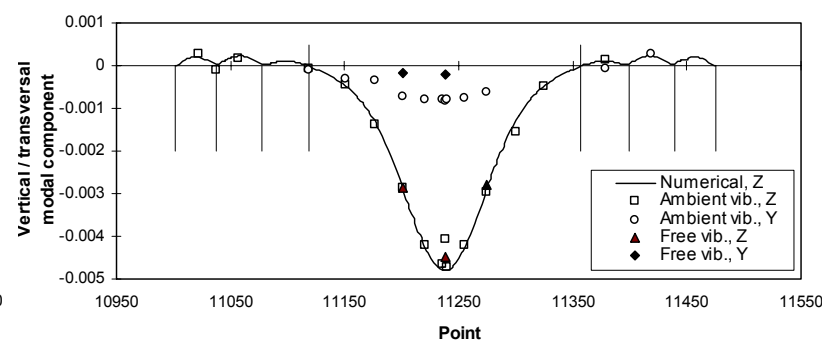


Freq. $=0.572 \mathrm{~Hz}-2 \mathrm{nd}$ torsion mode

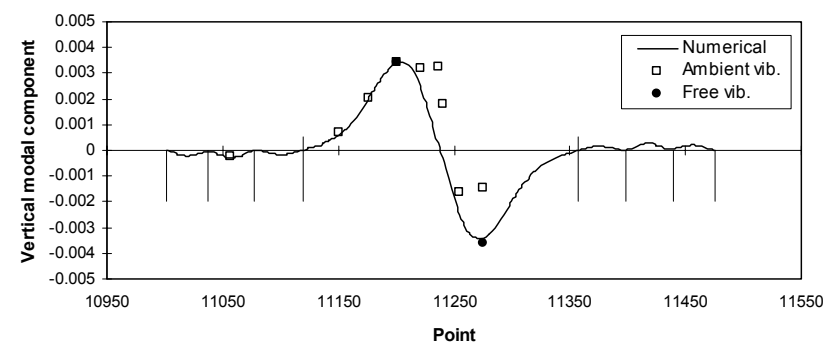

Freq. $=0.619 \mathrm{~Hz}-2 \mathrm{nd}$ torsion + transversal bending mode

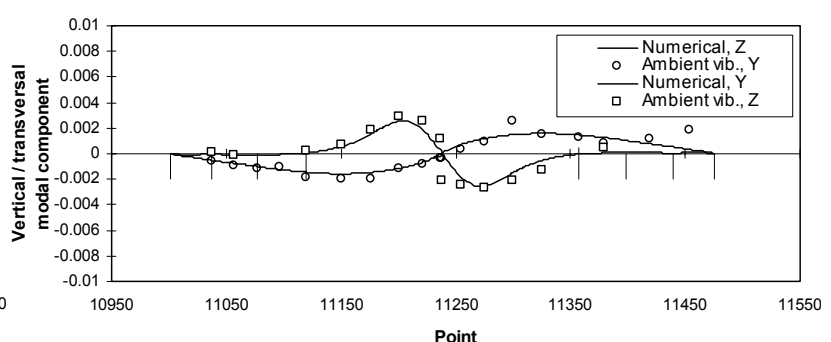

Fig.5: Some of the identified modal shapes of the deck

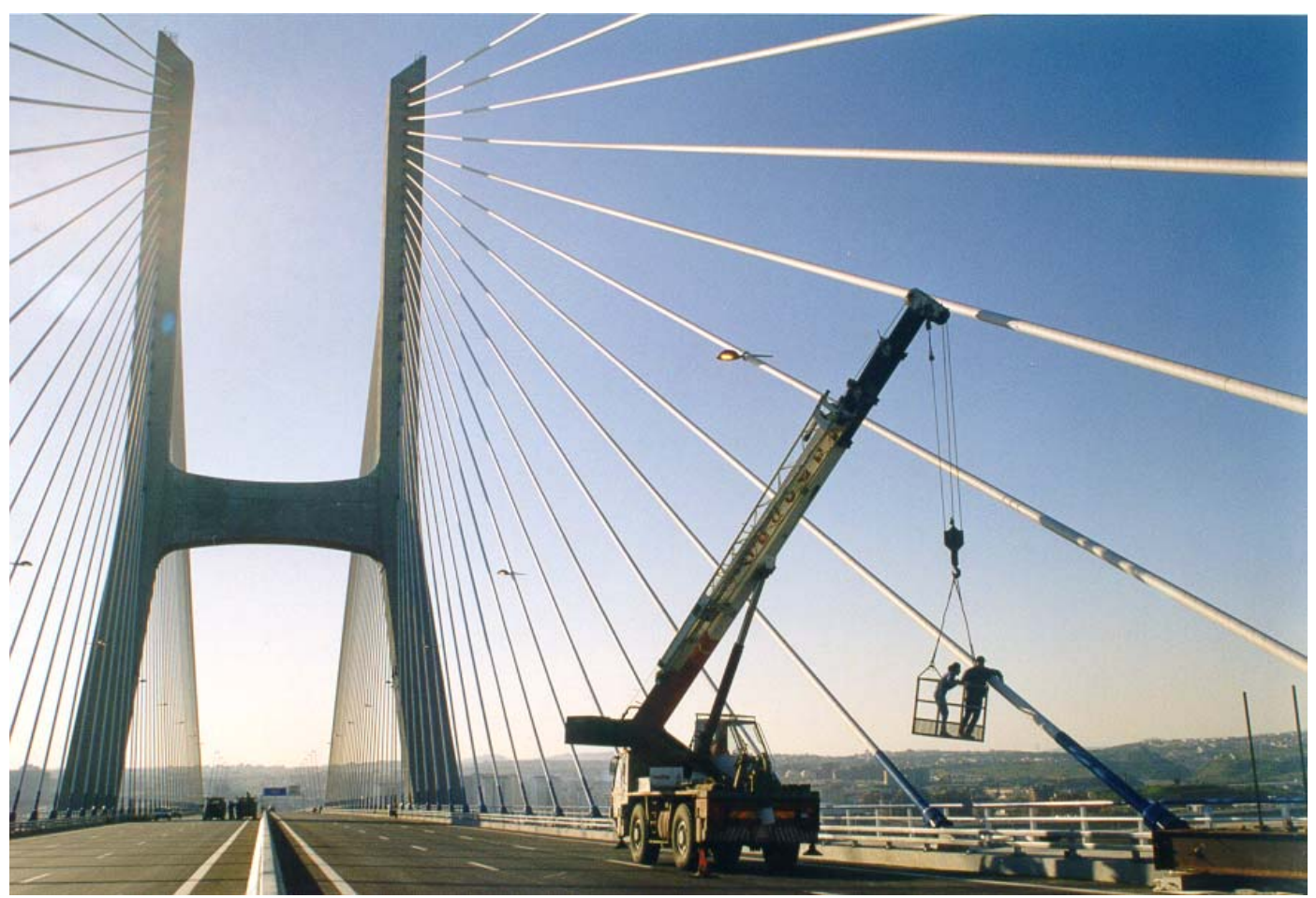

Fig. 6: Installation of accelerometers on stay cables 


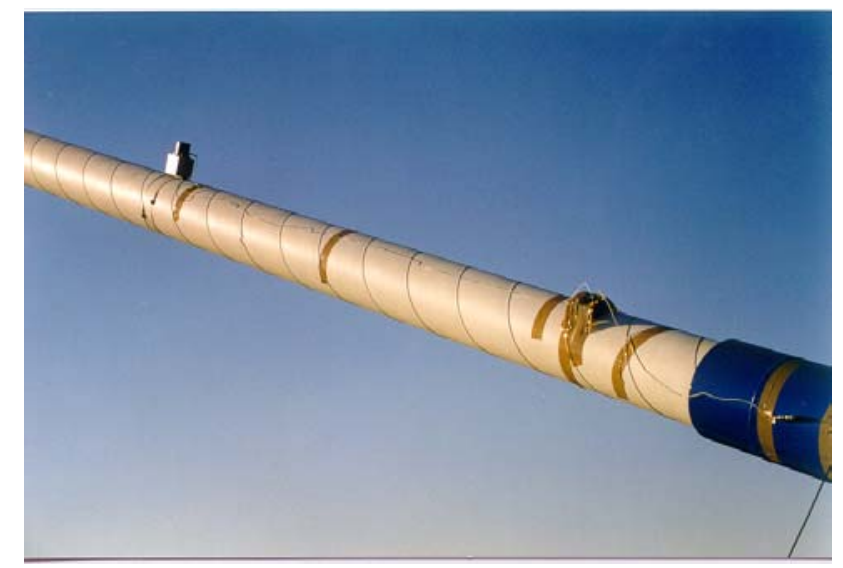

(a)

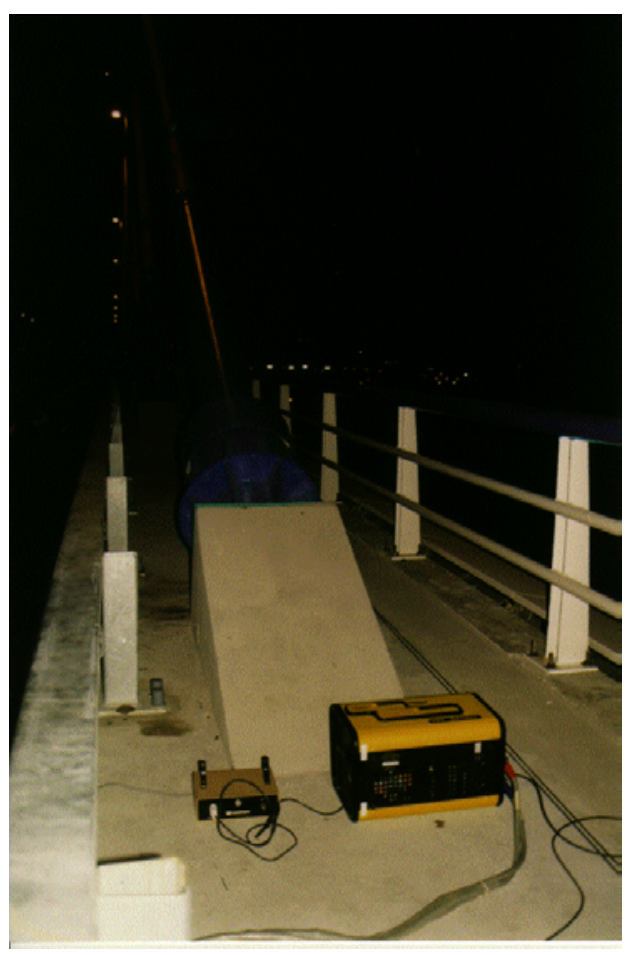

(b)

Fig. 7: (a) Measurement of vibrations in a stay-cable using an accelerometer; (b) Laser head placed on the deck surface hitting a stay-cable with a vertical laser beam (at night)

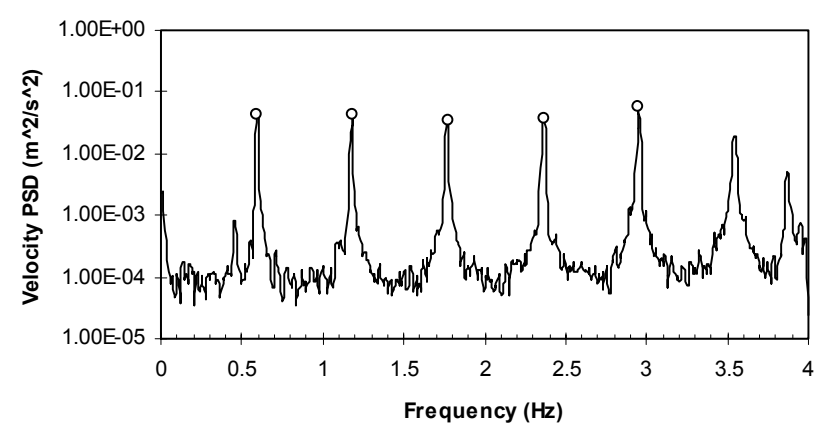

(a)

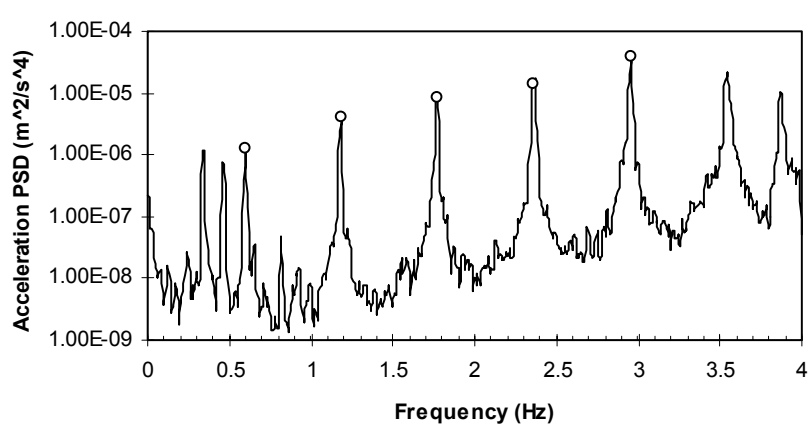

(b)

Fig. 8: Average power spectra of the ambient response of a stay cable:

(a) using the laser sensor; (b) using the accelerometer

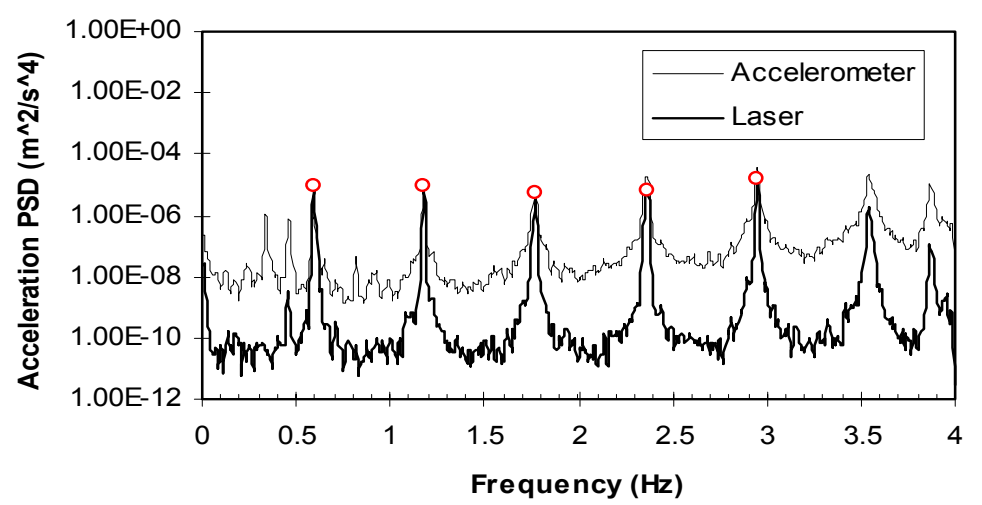

Fig. 9: Comparison of acceleration average power spectra of the ambient response of a stay cable 


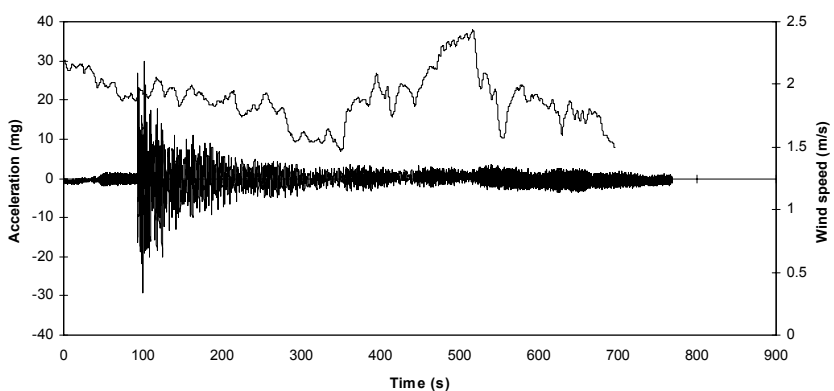

(a)

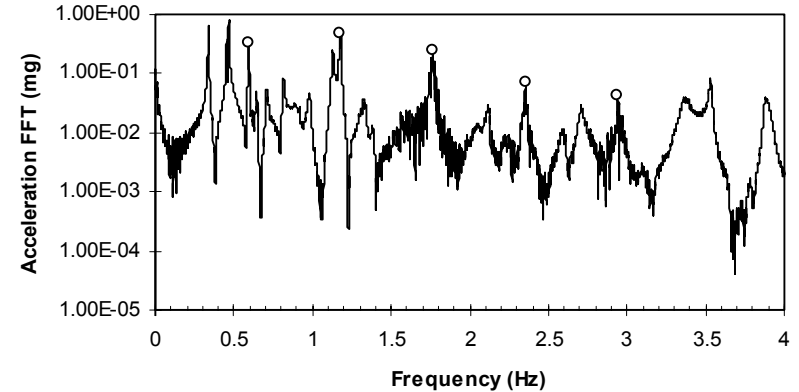

(b)

Fig. 10: Response of the stay cable during the free vibration test of the bridge: (a) Cable response and wind speed at $1 / 2$ span; (b) FFT of the cable response 